\title{
AN ON-LINE TEAM-EFFECTIVENESS LEARNING SYSTEM
}

\author{
Sheridan, P K; To, P M; Evans, G J; Reeve, D W \\ Institute for Leadership Education in Engineering and Dept. of Chemical Engineering and Applied Chemistry, University of Toronto, \\ Ontario Canada \\ patricia.sheridan@utoronto.ca
}

\section{INTRODUCTION}

This paper outlines the design and use of a new on-line Teameffectiveness Learning System (TELS) at the University of Toronto that supports student learning of individual teameffectiveness competencies in their team-based projects. Within the first year engineering design courses at the University of Toronto, students work in teams of 3-7 students to address realworld problems that are provided to them by stakeholders. In these courses, students historically were provided with lectures and models of effective teamwork and were then expected to determine how to work effectively as a team on their own. Course assessments of student teamwork consisted of determining the percent work contribution to final deliverables of each student. While this allowed instructors to determine if grade modifications were necessary, it did not provide the students any assessment or support of how they were developing as team members. Ultimately, no intentional, experiential learning opportunity existed around developing the skills necessary to be an effective team member.

To address this need, the TELS was developed as a complementary tool for integration in team-based project courses as a means of developing individual team-effectiveness competencies in students.

\section{THE TEAM-EFFECTIVNESS LEARNING SYSTEM}

The TELS was designed to be a fully-integrated learning space which could be dropped into any engineering team-based project in which the students work on a shared deliverable for more than 4 weeks together. The objectives of integrating this system into student teams were twofold. First, we endeavoured to move students away from a work-only focus in their teams, and to begin thinking about the other components of teamwork that are necessary to create an effective environment. Second, we wanted to develop individual, transferable teamwork behaviours in the students that would extend beyond the project team in which they used the TELS.

The TELS comprises four components which integrate together to form a personalized learning experience that supports student development in their areas of weakness. The TELS provides lessons and exercises on effective teamwork at the team and individual levels. Students first complete self- and peer-assessments in their project teams using the Teameffectiveness Inventory presented in Table 1. The Teameffectiveness Inventory outlines 12 behavioural competencies across three aspects of team-effectiveness (organisational, relational and communication aspects) that are necessary to be an effective team member. Based on anonymized feedback they receive from their peers, students are guided toward lessons and strategies on the on-line system to help them develop their weakest competencies. Individual-level lessons describe the competencies in the team-effectiveness inventory, and teamlevel instruction provides students with tools to make their teams function more cohesively and to prevent dysfunction.

\section{STUDENT USE OF THE SYSTEM}

Launched in Fall 2013, the TELS has been used in two firstyear engineering design courses at the University of Toronto of 250 and 1000 students. In each semester-long course, students were asked to complete a self- and peer-assessment using the team-effectiveness inventory at the mid-point and end of their design project work. After completing each assessment, students were provided anonymized feedback from their team members and were directed towards the lessons on the system that would best address their areas of weakness.

Table 1: Team-effectiveness inventory competencies grouped by their aspect of individual team-effectiveness.

\begin{tabular}{c}
\hline Organisational Aspect \\
Attend team meetings prepared \\
Help to plan and organize workflow \\
Do their fair share of the work \\
Deliver their work on time \\
\hline Relational Aspect \\
\hline Show respect for team members \\
Seek and include input from team members \\
Listen and pay attention to team members \\
Demonstrate accountability \\
Communication Aspect \\
Openly express ideas and opinions \\
Promote productive discussion \\
Exchange information in a timely manner \\
Raise contentious issues in a constructive way
\end{tabular}

Preliminary analysis of the effectiveness of the system has investigated student use of the system in terms of what they access and when they access it. Eighty-five percent (85\%) of students across both courses completed the mid-point evaluation, and seventy-three percent (73\%) logged on to the system to review their feedback from their peers. Sixteen percent (16\%) of students reviewed lessons on the TELS after having received their feedback. Of the students that did review lessons, on average each student accessed 2-4 lessons on individual team-effectiveness competencies, with all lessons being accessed by at least one student. Lessons corresponding to competencies cited by students as creating team dysfunction when lacking from a team (competencies 1-7 of Table 2) were accessed more frequently than other competencies.

Table 2: Individual team-effectiveness competencies ranked in order from most accessed to least accessed on the TELS.
Help to plan and organize workflow
Exchange information in a timely manner
Attend team meetings prepared
Raise contentious issues in a constructive way
Demonstrate accountability
Do their fair share of the work
Deliver their work on time
Openly express ideas and opinions
Listen and pay attention to other team members
Promote productive discussion
Show respect to other team members
Seek and include input from team members

\section{CONCLUSION}

Preliminary findings indicate that students use the Teameffectiveness learning system for feedback on their team work. However, further research needs to take place to determine how the lessons on the TELS can better support student development of effective teamwork behaviours. 